\title{
Approximate Linear ANAlysis of CONCRETe FRACTURE BY R-CURVES
}

\author{
By Zdeněk P. Bažant, ${ }^{1}$ F. ASCE and Luigi Cedolin, ${ }^{2}$ M. ASCE
}

\begin{abstract}
AвstRAct: Using linear elastic fracture analysis, the energy consumed per unit length of fracture (fracture energy) varies with the crack length, as described by the resistance curve (R-curve). This concept, originally proposed for metals, is developed here into a practical, applicable form for concrete. The energy release rate is determined by an approximate linear elastic fracture analysis based on a certain equivalent crack length, which differs from the actual crack length, and is solved as part of structural analysis. It is shown that such an analysis, coupled with the R-curve concept, allows achieving satisfactory fits of the presently existing fracture data obtained with three-point and four-point bent specimens. Without the R-curve, the use of an equivalent crack length in linear analysis is not sufficient to achieve a satisfactory agreement with these data. The existing data can be described equally well with various formulas for the $R$-curve, and the material parameters in the formula can vary over a relatively broad range without impairing the representation of test data. Only the overall slope of the R-curve, the initial value, and the final value are important. A parabola seems to be the most convenient shape of $R$-curve because the failure load may then be solved from a quadratic equation. For the general case, a simple algorithm to calculate the failure load is given. Deviations from test data are analyzed statistically, and an approximate relationship of the length parameter of the R-curve to the maximum aggregate size is found.
\end{abstract}

\section{INTRODUCTION}

Due to the large size of the fracture process zone at the crack front, concrete structures do not follow linear elastic fracture mechanics, except when the cross section is extremely large compared to the aggregate size. Nevertheless, engineers need to be able to use linear elastic fracture mechanics at least in some approximate, equivalent sense because nonlinear fracture analysis is much more complicated. Since concrete does not behave plastically under tensile situations, the exterior of the fracture process zone is essentially elastic. Therefore, the stress field farther away from the fracture process zone should be close to that corresponding to a linear fracture mechanics solution for a certain equivalent crack length.

As it turns out, however, this does not suffice to achieve good agreement with fracture test results. Evaluating these results by linear elastic fracture mechanics, one finds that the fracture energy, i.e., the energy consumed by fracture per unit crack length, is variable. Thus, in addition to considering a certain equivalent crack length instead of the actual crack length, one must also take into account the variation of the fracture energy. The situation for concrete happens to be the same as for ductile

'Prof. of Civ. Engrg. and Dir., Center for Concrete and Geomaterials, Technological Inst., Northwestern Univ., Evanston, Ill. 60201.

${ }^{2}$ Visiting Scholar, Northwestern Univ.; Prof. on leave from Dept. of Struct. Engrg., Politecnico di Milano, Italy.

Note.-Discussion open until November 1, 1984. To extend the closing date one month, a written request must be filed with the ASCE Manager of Technical and Professional Publications. The manuscript for this paper was submitted for review and possible publication on August 25, 1983. This paper is part of the Joumal of Structural Engineering, Vol. 110, No. 6, June, 1984. CASCE, ISSN 07339445/84/0006-1336/\$01.00. Paper No. 18954. 
fracture of metals, for which the fracture energy variation has been studied extensively (6). This variation is described by the plot of fracture energy (or fracture toughness) versus the crack extension, $c$, from a notch or smooth surface. This plot is called the resistance curve or R-curve.

As is well known, the R-curve for any given material cannot be unique unless the crack length, $c$, is negligible compared to the dimensions of the cross section, the ligament, and the distance to the nearest applied load. Otherwise, the shape of the R-curve depends on these parameters and on the geometrical shape of the structure and the nature of loading. The shape of the R-curve can be approximately calculated by various methods (for concrete, see Ref. 28, 3).

As it appears, however, the shape of the R-curve does not vary strongly from one type of structure (specimen) to another, and also it does not have a strong effect on calculation results, as will be seen later. Thus, one may postulate a priori a certain suitable fixed shape of the R-curve for all situations, which allows a great simplification of analysis. This was proposed for metals by Krafft, et al. $(6,16)$ and has been widely used in ductile fracture.

The present study shows that the R-curve approach, combined with linear elastic fracture analysis for a certain effective crack length, which differs from the actual crack length, allows achieving a good agreement with the available fracture test data for concrete.

\section{Review of R-Cunve Concept}

Let $c=a-a_{0}$ in which $a_{0}=$ length of the notch [Fig. $1(a)$ ]; and $a=$ total length of crack and notch. Consider that the fracture energy, $G_{c}$, is a certain given function of crack extension, $c$, i.e., $G_{c}=G_{c}(c)$. The energy that must be supplied to the structure to produce the crack is $U$ $=\int G_{c}(c) d a-W(a)$ if the thickness of the structure in the third dimension is considered as unity; here $W$ is the total release of strain energy from the structure (or specimen). An equilibrium state of fracture occurs when no energy needs to be supplied to change $a$ by $\delta a$ and none is released, i.e., when $\delta W=0$. Since $\delta U=(\partial U / \partial a) \delta a=0$, in which $\partial U /$ $\partial a=G_{c}-W^{\prime}=0$, and $W^{\prime}=\partial W / \partial a$, it follows that fracture equilibrium occurs when

$W^{\prime}(a)=G_{c}(c) \quad$ (equilibrium)

The equilibrium fracture state is stable if the second variation $\delta^{2} U$ is positive. Since $\delta^{2} U=\left(\partial^{2} U / \partial a^{2}\right) \delta a^{2}$ and $\partial^{2} U / \partial a^{2}=\partial G_{c} / \partial a-\partial W^{\prime} / \partial a$, the condition for stability of fracture and the limit of stability, i.e., the failure, are given by

$$
\begin{aligned}
\frac{\partial G_{c}(c)}{\partial c}-\frac{\partial W^{\prime}(a)}{\partial a} & >0 \quad(\text { stable }) \ldots \ldots \ldots \ldots \ldots \ldots \ldots \ldots \ldots \ldots \ldots \ldots \ldots \ldots \ldots \ldots \ldots \ldots \ldots \ldots \ldots \ldots \ldots \ldots \ldots \ldots \ldots \ldots \ldots \ldots
\end{aligned}
$$

For most structures, the strain energy release rate increases as the crack grows, i.e., $W^{\prime}(a)>0$. By elastic structural analysis, one can calcte

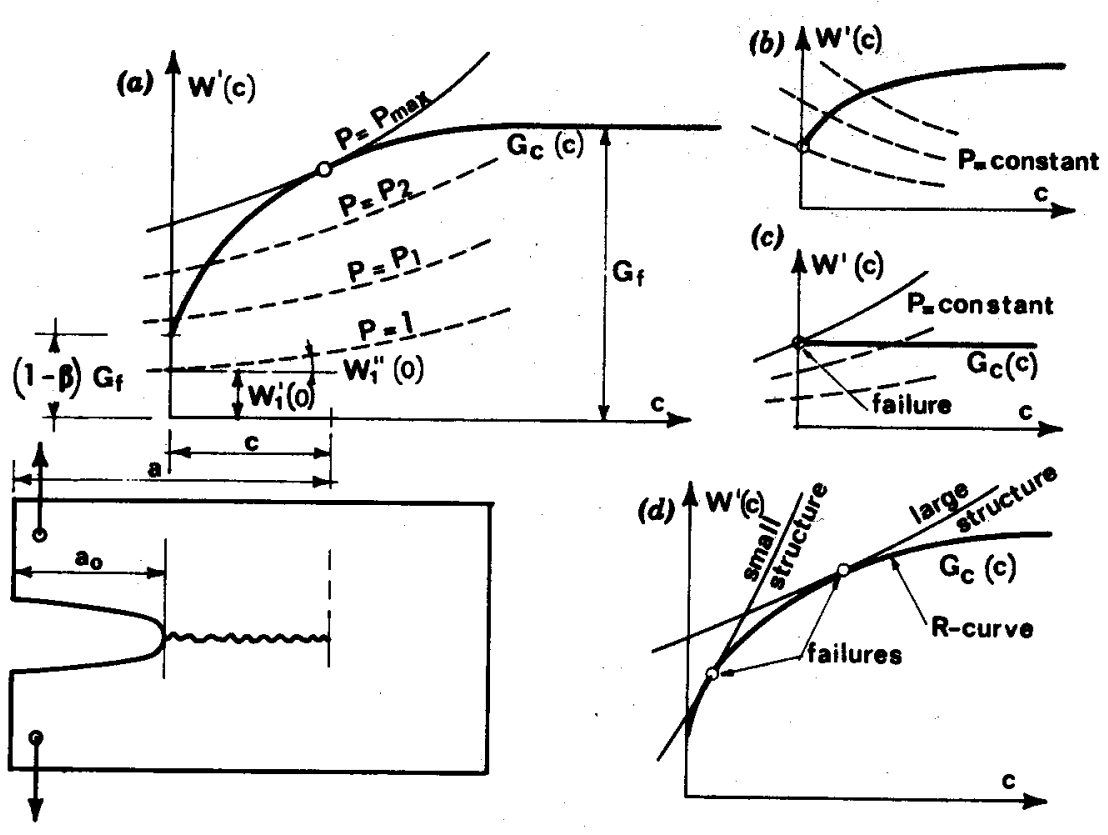

FG. 1.-R-Curves and Diegrams of Enorgy Releace Rate

late the curve $W_{1}^{\prime}(a)$ corresponding to a unit load, $P=1$. Then, for any load $P$

$W^{\prime}(a)=P^{2} W_{1}^{\prime}(a)$

as can be deduced by dimensional analysis. Fig. 1(a) shows the curves, $W^{\prime}(a)$, for a succession of increasing $P$-values, $P_{1}, P_{2}, P_{3}, \ldots$ According to Eq. 1, the equilibrium states of crack extension for various load values are given by the intersections of these curves with the given curve $G_{c}(c)$. According to Eq. 2, these equilibrium states are stable if at the point of intersection the slope of the $G_{c}(a)$-curve is larger than the slope of the $W^{\prime}(a)$-curve (see Fig. 1). As the crack grows, the difference between the slopes, $\delta G_{c} / \partial a$ and $\partial W^{\prime} / \partial a$, gradually diminishes until, at a certain point, the slopes become equal (Fig. 1); this is then the critical state at which the structure fails. Beyond this point the crack extension is unstable and occurs dynamically since there is an excess of energy release that must go into kinetic energy.

In the rare case that $W^{\prime}<0$ for all $a$, Eq. 2 is always satisfied, and the crack is then stable for all $a$ [Fig. 1(b)].

In the case that $G_{c}$ is constant, Eq. 2 reads $0>\partial W^{\prime} / \partial a$. This condition can never be satisfied if $W^{\prime}$ increases with $a$ [Fig. $1(c)$ ]. Thus, if a stable crack growth from a notch is observed in experiments, it implies that $G_{c}$ cannot be constant but must increase, provided the test specimen geometry is such that $W^{\prime}$ increases with $a$.

Comparing structures that are geometrically similar (including their notches) but of different sizes, the curves of $W^{\prime}(c)$ are also of similar 
shape (i.e. related by affinity transformation), while the curve $G_{c}(c)$ remains the same. This causes failure to occur at a larger $c$ for a larger structure, as shown in Fig. 1(d).

\section{Calculation of Falluae load and Analysis of Fracture Data}

The energy release rate, $W^{\prime}$, to be used in Eq. 2 may be determined by linear elastic fracture analysis using various methods. For typical fracture specimens, highly accurate approximations are available (see Refs. $6,15,19,24)$. For example, for an infinitely long strip of width $L$ and unit thickness, containing a symmetric crack of length $2 a$ normal to the strip sides, and loaded at infinity by axial load $P$, the stress intensity factor is

$K_{1} \simeq \frac{P}{L}\left(L \tan \frac{\pi a}{L}\right)^{1 / 2}$

from which $W^{\prime}(a)=K_{1}^{2} / E$ in which $E=$ Young's modulus (15). For the three-point bent specimen and the four-point bent specimen (Fig. 2)

$K_{1} \simeq \sqrt{\pi a} \frac{P L}{b d^{2}} f_{3}(\alpha)$,

$f_{3}(\alpha)=1.635-2.603 \alpha+12.30 \alpha^{2}-21.27 \alpha^{3}+21.86 \alpha^{4}$

$K_{1} \simeq \sqrt{\pi a} \frac{P L}{b d^{2}} f_{4}(\alpha)$,

$f_{4}(\alpha)=1.12-1.39 \alpha+7.32 \alpha^{2}-13.07 \alpha^{3}+13.99 \alpha^{4}$

in which $\alpha=a / d ; d=$ beam depth; $L=$ beam span, $b=$ beam width; and for the four-point bent specimen, the loads are applied symmetrically at distances $L / 3$ from the supports $(15,20,24)$. These expressions have been used in the analysis of the test data described later.

For structures of arbitrary geometry, one may determine the values of $W^{\prime}(a)$ for various small $a$ by finite element analysis. Highly accurate results can be obtained with the use of singular elements, however, for concrete it makes no sense to strive for errors less than about $1 \%$. Then it suffices to use a regular grid of nonsingular elements, for which the crack may be modeled with about the same accuracy either as a sharp interelement crack or as a band of cracked elements of a single-element width $(1-5,19)$, the latter being usually easier for programming. $W^{\prime}(a)$ may be estimated either from the difference between the total potential
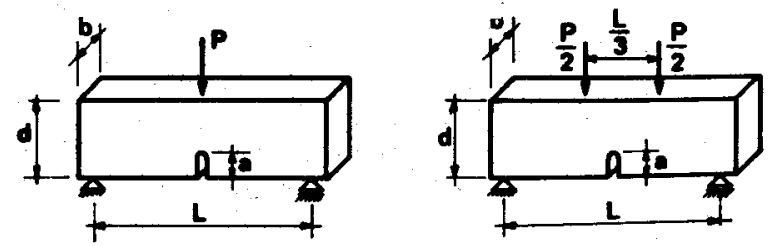

F1G. 2-Three-Polnt Bent and Four-Point Bent Specimene energies of the structure for two adjacent values of $a$, or from the field of displacements or stresses near the crack front.

Further, one needs to choose a priori a suitable formula for the fracture energy, $G_{c}$, of the material. Experiments show (25-28) that for concrete, similarly to other materials, $G_{c}$ increases as a function of $c$ and seems to approach a certain asymptotic value, $G_{f}$. Existence of the asymptotic value is also indicated theoretically (28). Measurements are, however, quite scattered and do not permit distinguishing too well between various possible expressions for $G_{c}(c)$. The following three formulas have been examined in calculations:

$G_{c}(c)=G_{f}\left(1-\beta e^{-c / c_{m}}\right)$

$G_{c}(c)=G_{f}\left[1-\beta\left(\frac{c}{c_{m}}-1\right)^{2}\right]$

for $0 \leq c \leq c_{m}, G_{c}(c)=G_{f}$ for $c \geq c_{m}$.

$G_{c}(c)=G_{f}\left[1-\beta\left(1-\frac{c}{c_{m}}\right)\right]$

for $0 \leq c \leq c_{m}, G_{c}(c)=G_{f}$

in which $G_{f}, \beta$, and $c_{m}=$ material parameters to be found empirically. A more complicated formula with two additional parameters, $q$ and $r$ $G_{c}(c)=G_{f}\left\{1-\beta \exp \left[-\left(c / c_{m}\right)^{q}\right]\right\}$, was also tried; however, no appreciable improvement in the fits of test data could be achieved.

Parameter $c_{m}$ characterizes the length over which $G_{c}$ approaches its final value, $G_{f}$. Since the dimensions of the fracture process zone in concrete appear to be in a certain fixed ratio to the maximum aggregate size $d_{a}$, as suggested by various recent analyses $(1,3)$, it seems reasonable to assume that

$c_{m}=m d_{a}$

in which $m$ may be considered the same for all concretes.

When $c_{m}$ is fixed, the formulas in Eqs. 7-9 may be written in the form

$G_{c}(c)=G_{f}-b x$

in which $b=G_{f} \beta$ and $x=\exp \left(-c / c_{m}\right)$ for Eq. $7 ; x=\left(c / c_{m}-1\right)^{2}$ or $x=$ $\left(c / c_{m}-1\right)$ for $c<c_{m}$; and $x=0$ for $c \geq c_{m}$ in the case of Eq. 8 or 9 . Since Eq. 11 is linear, linear statistical regression analysis may be used to analyze test data on the R-curves reported in the literature $(9,23,25,27)$. Such analyses have been carried out first for each data set taken individually, and the coefficients of variation $\omega_{i}$ for the deviations of measured data from the regression line (Eq. 11) have been evaluated for each data set by a computer for a series of values of $c_{m}$ ranging from 1 to 50 . A few examples of such plots are demonstrated in Figs. $3-5$, respectively, fo: Eqs. 7-9.

Subsequently, for each $c_{m}$ value, the combined coefficient of variation for all data sets was calculated as $\bar{\omega}=\left(\Sigma_{i} \omega_{i}^{2} / n\right)^{1 / 2}$ in which $i=1,2, \ldots$ $n$ are the data sets used. It appeared that the smallest $\bar{\omega}$ occurs for the exponential formula (Eq. 7) roughly for $c_{m}=12$, and for the parabolic 
shape (i.e. related by affinity transformation), while the curve $G_{c}(c)$ remains the same. This causes failure to occur at a larger $c$ for a larger structure, as shown in Fig. 1(d).

\section{Calculation of Fallure load and Amalysis of Fracture Data}

The energy release rate, $W^{\prime}$, to be used in Eq. 2 may be determined by linear elastic fracture analysis using various methods. For typical fracture specimens, highly accurate approximations are available (see Refs. $6,15,19,24)$. For example, for an infinitely long strip of width $L$ and unit thickness, containing a symmetric crack of length $2 a$ normal to the strip sides, and loaded at infinity by axial load $P$, the stress intensity factor is

$K_{1} \simeq \frac{P}{L}\left(L \tan \frac{\pi a}{L}\right)^{1 / 2}$

from which $W^{\prime}(a)=K_{1}^{2} / E$ in which $E=$ Young's modulus (15). For the three-point bent specimen and the four-point bent specimen (Fig. 2)

$K_{1} \simeq \sqrt{\pi a} \frac{P L}{b d^{2}} f_{3}(\alpha)$,

$f_{3}(\alpha)=1.635-2.603 \alpha+12.30 \alpha^{2}-21.27 \alpha^{3}+21.86 \alpha^{4}$

$K_{1} \simeq \sqrt{\pi a} \frac{P L}{b d^{2}} f_{4}(\alpha)$,

$f_{4}(\alpha)=1.12-1.39 \alpha+7.32 \alpha^{2}-13.07 \alpha^{3}+13.99 \alpha^{4}$

in which $\alpha=a / d ; d=$ beam depth; $L=$ beam span, $b=$ beam width; and for the four-point bent specimen, the loads are applied symmetrically at distances $L / 3$ from the supports $(15,20,24)$. These expressions have been used in the analysis of the test data described later.

For structures of arbitrary geometry, one may determine the values of $W^{\prime}(a)$ for various small $a$ by finite element analysis. Highly accurate results can be obtained with the use of singular elements, however, for concrete it makes no sense to strive for errors less than about $1 \%$. Then it suffices to use a regular grid of nonsingular elements, for which the crack may be modeled with about the same accuracy either as a sharp interelement crack or as a band of cracked elements of a single-element width $(1-5,19)$, the latter being usually easier for programming. $W^{\prime}(a)$ may be estimated either from the difference between the total potential
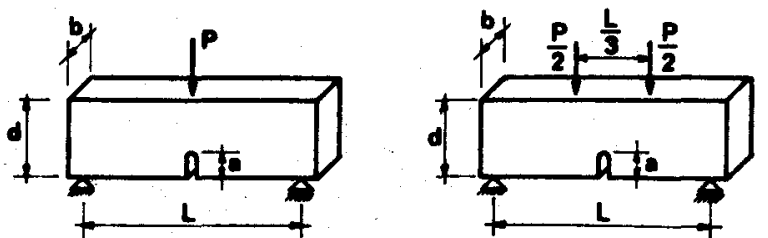

FiG. 2.-Three-Point Bent and Four-Point Bent Specimens energies of the structure for two adjacent values of $a$, or from the field of displacements or stresses near the crack front.

Further, one needs to choose a priori a suitable formula for the fracture energy, $G_{c}$, of the material. Experiments show (25-28) that for concrete, similarly to other materials, $G_{c}$ increases as a function of $c$ and seems to approach a certain asymptotic value, $G_{f}$. Existence of the asymptotic value is also indicated theoretically (28). Measurements are, however, quite scattered and do not permit distinguishing too well between various possible expressions for $G_{c}(c)$. The following three formulas have been examined in calculations:

$G_{c}(c)=G_{f}\left(1-\beta e^{-c / c_{m}}\right)$

$G_{c}(c)=G_{f}\left[1-\beta\left(\frac{c}{c_{m}}-1\right)^{2}\right]$

for $0 \leq c \leq c_{m}, G_{c}(c)=G_{f}$ for $c \geq c_{m}$.

$G_{c}(c)=G_{f}\left[1-\beta\left(1-\frac{c}{c_{m}}\right)\right]$

for $0 \leq c \leq c_{m}, G_{c}(c)=G_{f}$

for $c \geq$

in which $G_{f}, \beta$, and $c_{m}=$ material parameters to be found empirically. A more complicated formula with two additional parameters, $q$ and $r$, $G_{c}(c)=G_{f}\left\{1-\beta \exp \left[-\left(c / c_{m}\right)^{q}\right]\right\}^{r}$, was also tried; however, no appreciable improvement in the fits of test data could be achieved.

Parameter $c_{m}$ characterizes the length over which $G_{c}$ approaches its final value, $G_{f}$. Since the dimensions of the fracture process zone in concrete appear to be in a certain fixed ratio to the maximum aggregate size, $d_{a}$, as suggested by various recent analyses $(1,3)$, it seems reasonable to assume that

$c_{m}=m d_{a}$

in which $m$ may be considered the same for all concretes.

When $c_{m}$ is fixed, the formulas in Eqs. 7-9 may be written in the form $G_{c}(c)=G_{f}-b x$

in which $b=G_{f} \beta$ and $x=\exp \left(-c / c_{m}\right)$ for Eq. $7 ; x=\left(c / c_{m}-1\right)^{2}$ or $x=$ $\left(c / c_{m}-1\right)$ for $c<c_{m}$; and $x=0$ for $c \geq c_{m}$ in the case of Eq. 8 or 9 . Since Eq. 11 is linear, linear statistical regression analysis may be used to analyze test data on the R-curves reported in the literature $(9,23,25,27)$. Such analyses have been carried out first for each data set taken individually, and the coefficients of variation $\omega_{i}$ for the deviations of measured data from the regression line (Eq. 11) have been evaluated for each data set by a computer for a series of values of $c_{m}$ ranging from 1 to 50 . A few examples of such plots are demonstrated in Figs. 3-5, respectively, for Eqs. 7-9.

Subsequently, for each $c_{m}$ value, the combined coefficient of variation for all data sets was calculated as $\bar{\omega}=\left(\Sigma_{i} \omega_{i}^{2} / n\right)^{1 / 2}$ in which $i=1,2, \ldots$ $n$ are the data sets used. It appeared that the smallest $\bar{\omega}$ occurs for the exponential formula (Eq. 7) roughly for $c_{m}=12$, and for the parabolic 

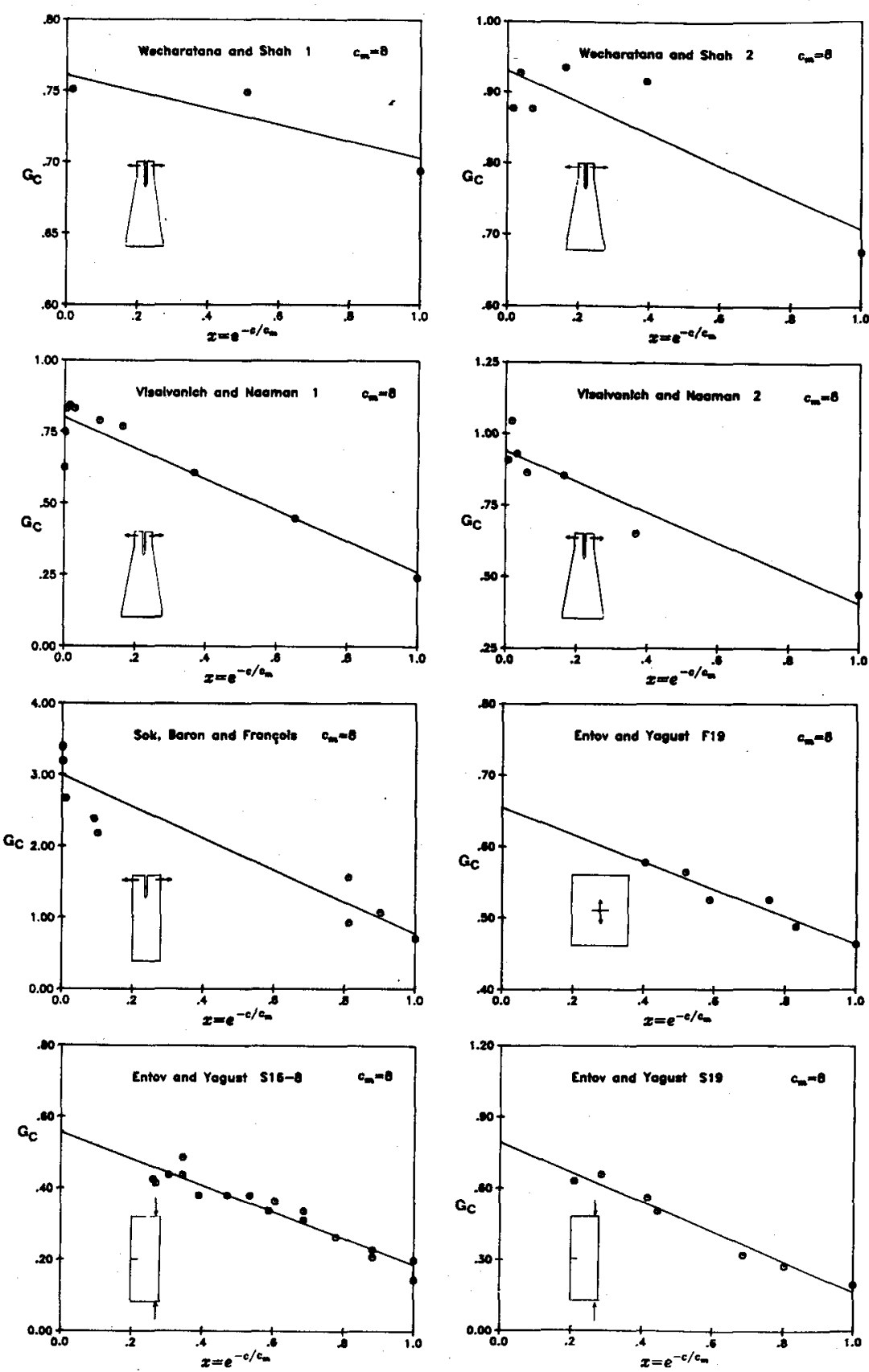

FIG. 3.-LInear Regression of R-Curve Data from Lherature According to Eqs. 7 and 11
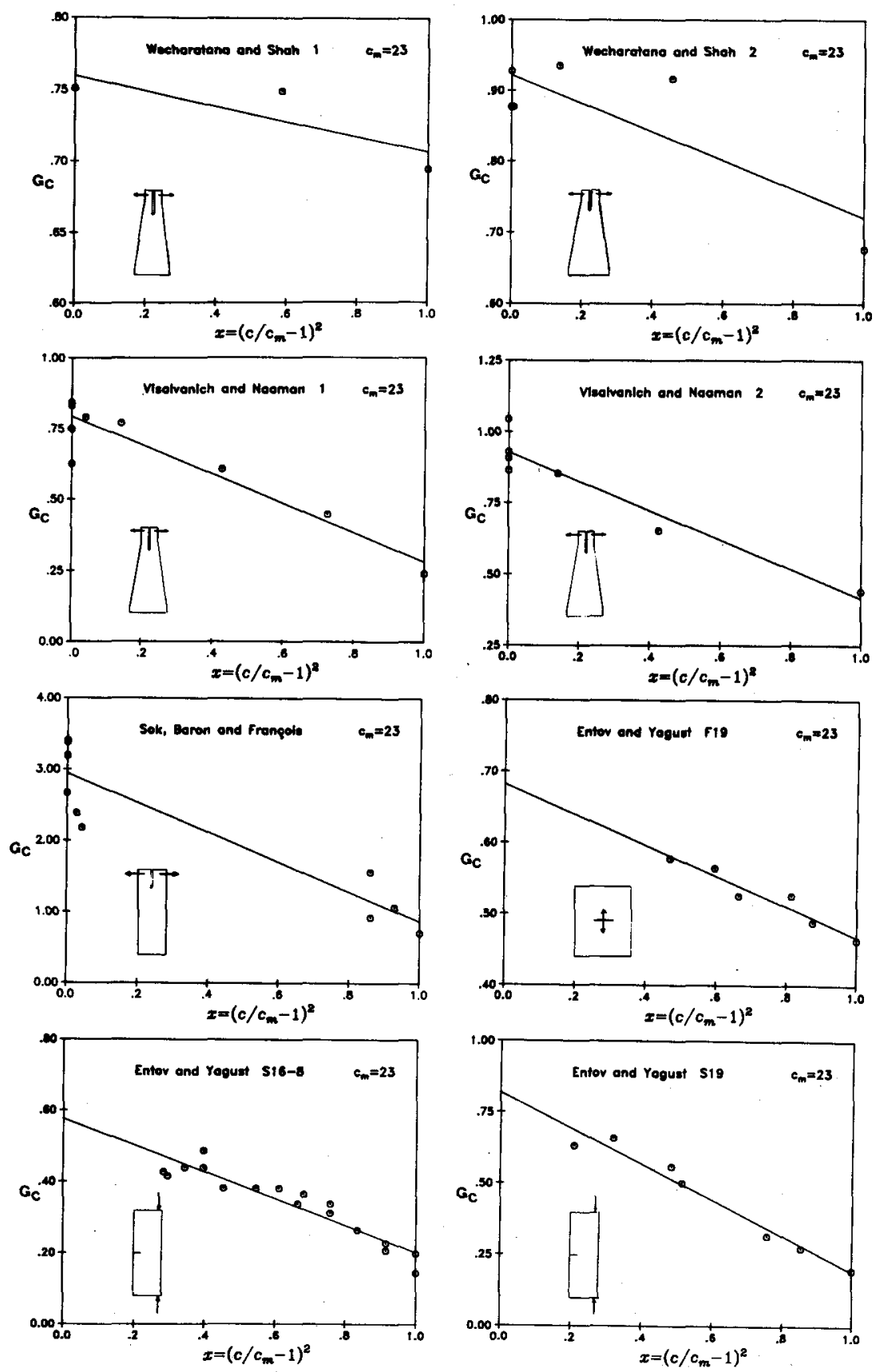

FIG. 4.-Linear Regression of R-Curve Data from Literature According to Eqs. 8 and 11 

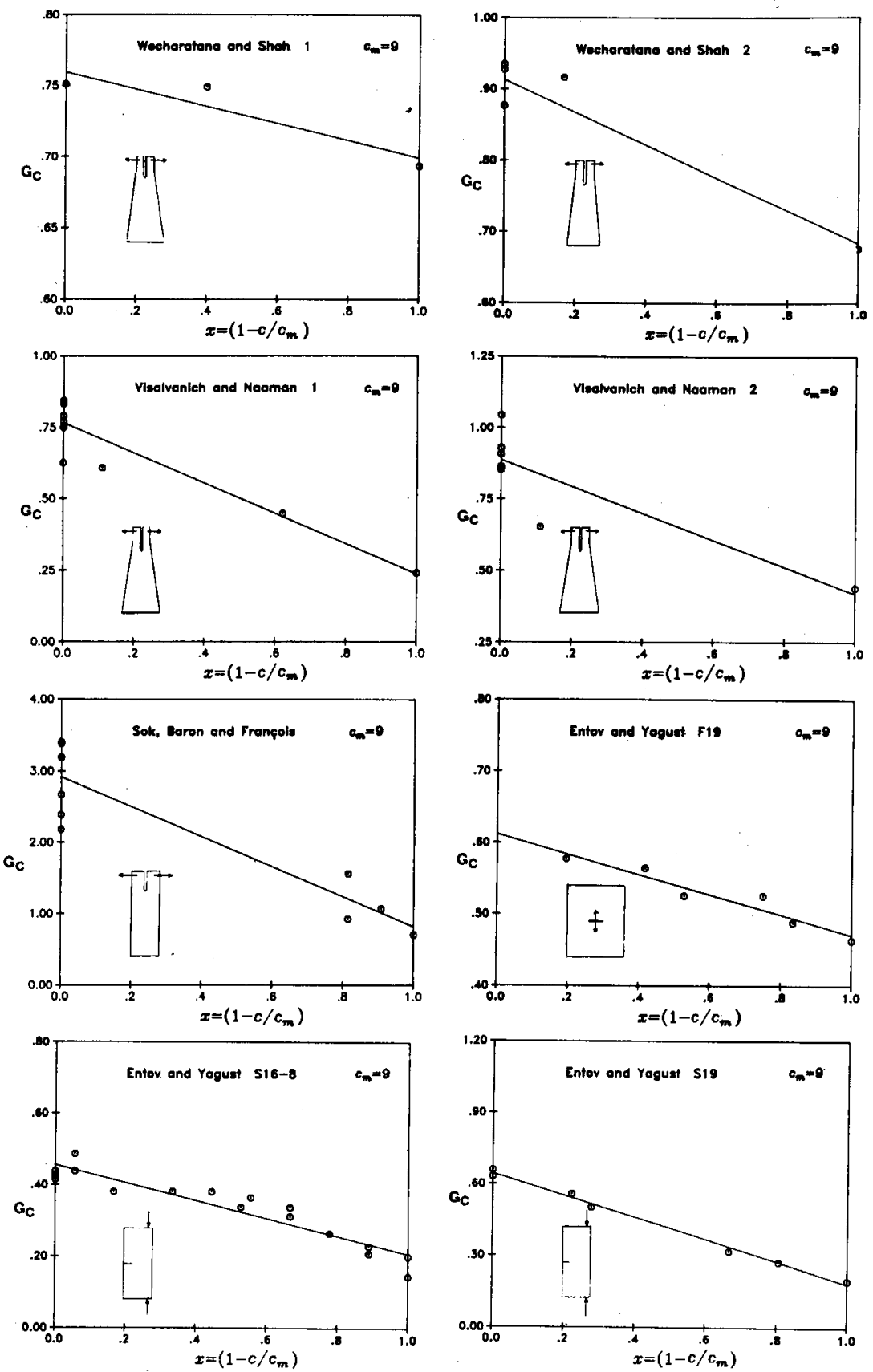

FIG. 5.-Linear Regression of R-Curve Data from Llterature According to Eqs. 9 and 11 formula roughly for $c_{m}=20$. However, these results are not very precise due to the scatter of data. This is apparent from Fig. $6(a-c)$ in which the values of $\bar{\omega}$ are plotted for various chosen values of $c_{m}$. Obviously, any value of $c_{m}$ between 5 and 25 is acceptable for the exponential formula, (a)

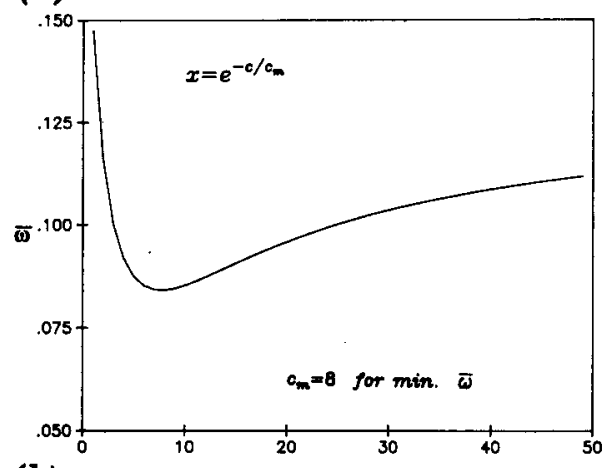

(b)

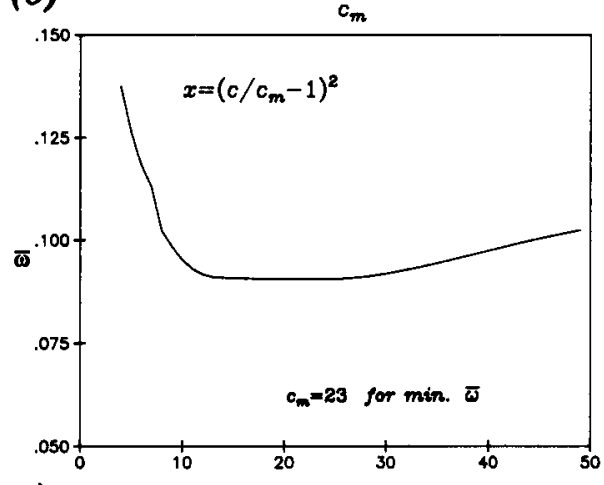

(c)

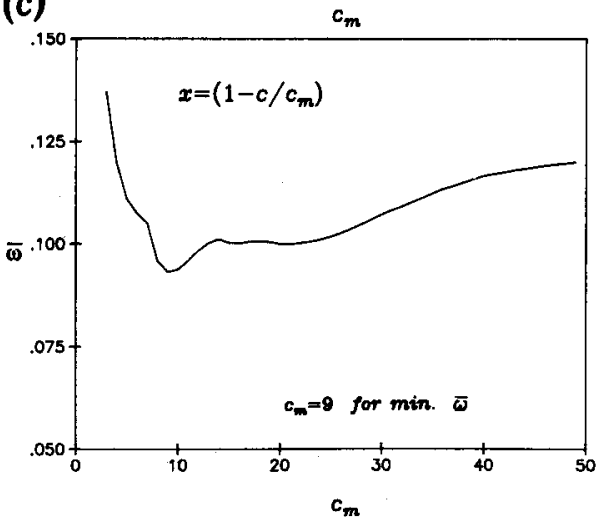

(d)

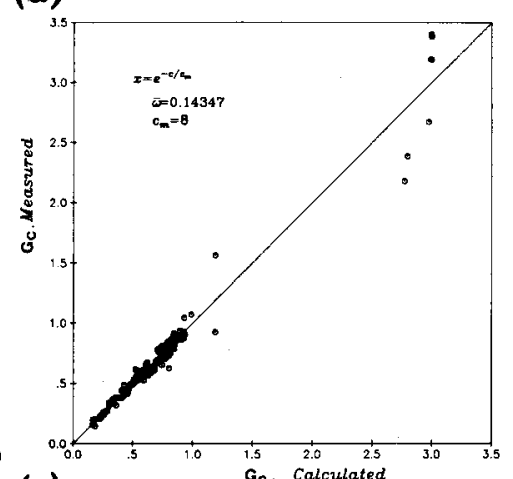

(e)

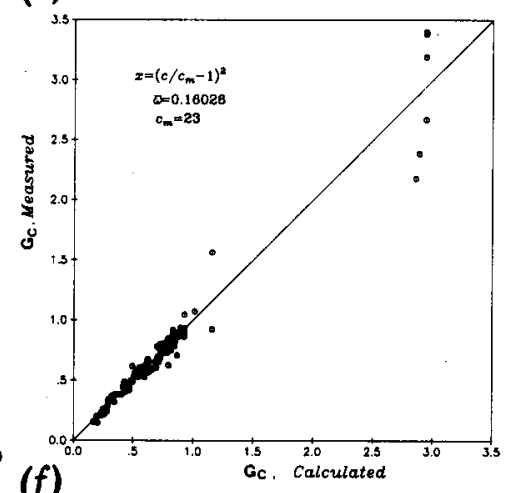

$(f)$

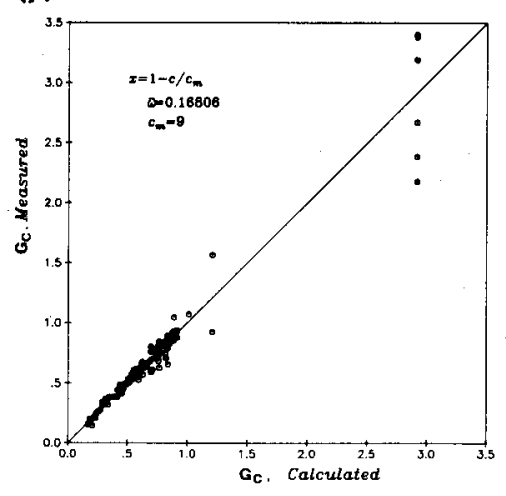

F1G. 6.- $(a)-(c)$ Coefficlent of Varlation $\bar{\omega}$ of Devlations from R-Curve Formulas; (d) $-(f)$ Regressions of Measured versus Calculated Fracture Energy 
and any value of $c_{m}$ between 12 and 30 is acceptable for the parabolic formula.

To sum up, the test data available in the literature permit obtaining optimum $c_{m}$ for all concretes. However, its value is quite uncertain, and only a certain range is indicated clearly.

Until less scattered experimental information is acquired, it is recommended to use

$c_{m}=12 d_{a}$ for Eq. 7, $c_{m}=20 d_{a}$ for Eq. 8

For these values, the measured values of $G_{c}$ for the test data from the literature $(9,23,25,27)$ were plotted versus the theoretical value of $G_{c}$ given by Eq. 7 or 8 . These plots, along with the coefficient of variation of the deviations from the regression line, are shown in Fig. $6(d-f)$. If the material showed no scatter and the theory were perfect, this plot would have to be a straight line of slope 1 passing through the origin. Deviations from such a straight line give an idea of the error.

The attempt has been made to obtain information on the value of $c_{m}$ from the data on maximum loads in fracture tests available in the literature. However, these data appear to be almost insensitive to the value of $c_{m}$ within a large range.

After determining functions $W^{\prime}(a)$ and $G_{c}(c)$, the maximum load (failure load) may be calculated with a computer by the following simple algorithm

1. Set the values of $G_{f}, \beta$, and $c_{m}$. Assign a small crack length increment, $\Delta a$, e.g., $0.01 a_{0}$, and set $a=a_{0}$.

2. Increment $a$, replacing it with $a+\Delta a$. Set $c=a-a_{0}$.

3. For each $a$, calculate $W_{i}(a)$ and $G_{c}(c)$. Since $W^{\prime}=W_{1}^{\prime} P^{2}$, the load corresponding to $a$ is found as $P=\left[G_{c}(c) / W_{1}^{\prime}(a)\right]^{1 / 2}$. If this value of $P$ is larger than the previous $P$-value, return to step 2 .

4. Now $\partial G_{c} / \partial c<\partial W^{\prime} / \partial a$, i.e., the specimen fails. Set $P_{\text {max }} \simeq P$. (More accurately, one could interpolate for the exact $a$ at which $\partial G_{c} / \partial c=\partial W^{\prime} /$ $\partial a$, but this is not necessary if $\Delta a$ is chosen to be as small as $0.01 a_{0}$.)

5. Print $P_{\max }$ and, in the case of test data analysis, evaluate the deviation from test data as $\Delta P_{\text {error }}=P_{m}-P_{\max }$ in which $P_{m}$ is the measured value of maximum load.

6. When several test series are to be fitted, repeat steps 1-5 for another case (e.g., another notch depth, $a_{0}$, or another beam depth, $h$, or another test series), and accumulate the sum, $\phi=\Sigma\left(\Delta P_{\text {errox }} / P_{0}\right)^{2}$, in which $P_{0}$ is the prediction of the failure load according to the bending strength theory, based on the net ligament section.

The foregoing algorithm (computer subroutine) is then used, together with a library optimization subroutine, such as the Marquardt-Levenberg's algorithm, to vary the values of $G_{f}, \beta$, and $c_{m}$ until those values which give $\min \phi$ are found.

A much simpler calculation of $P_{\max }$ is possible if the curve $W_{1}^{\prime}(a)$ can be approximated by a straight line within the range of interest, and if the parabolic formula for the R-curve (Eq. 8) is used. Suppose an estimate, $c=c_{0}$, of the crack extension at failure has been made (the simplest estimate is $\left.c_{0}=0\right)$. Then $W_{1}^{\prime}(a) \simeq W_{1_{0}}^{\prime}+W_{1_{0}}^{\prime \prime}\left(c-c_{0}\right)$ in which
$W_{1_{0}}^{\prime}$ is the value of $W_{1}^{\prime}$ at $a=a_{0}+c_{0}$; and $W_{1_{0}}^{\prime \prime}$ is the slope of the curve $W_{1}^{\prime}$ at that point. Eqs. 1 and $2 b$ may then be written as

$P^{2}\left[W_{1_{0}}^{\prime}+W_{1_{0}}^{\prime \prime}\left(c-c_{0}\right)\right]=G_{f}\left[1-\beta\left(\frac{c}{c_{m}}-1\right)^{2}\right]$

$P^{2} W_{\mathbf{1}_{0}}^{\prime \prime}=-2 \mathrm{G}_{f} \frac{\boldsymbol{\beta}}{c_{m}}\left(\frac{c}{c_{m}}-1\right)$

Elimination of $P$ then yields

$\left(c_{m}-c\right)^{2}-\left(2 \frac{W_{1_{0}}^{\prime}}{W_{1_{0}}^{\prime}}+c_{m}-c_{0}\right)\left(c_{m}-c\right)+\frac{c_{m}^{2}}{\beta}=0$.

which is a quadratic equation for $c$. After determining its smallest real solution, Eq. 13 or 14 yields $P=P_{\max }$

Alternatively, one may eliminate $c$ from Eqs. 13-14, which yields a quadratic equation for $P^{2}$ :

$W_{1_{0}}^{\prime \prime 2} \frac{c_{m}^{2}}{4 \beta G_{f}} P^{4}-\left[W_{1_{0}}^{\prime \prime}\left(c_{m}-c_{0}\right)+W_{1_{0}}^{\prime}\right] P^{2}+G_{f}=0$

from which the failure load $P=P_{\max }$ may be solved directly (the smaller one of two real positive solutions applies).

Even if $G_{c}$ is not given as a parabola, one may use the same procedure if the curve, $G_{c}$, is approximated by a parabola in the vicinity of the estimate, $c=c_{0}$. Such an approximation must be satisfactory if the estimate, $c_{0}$, is close.

TABLE 1.-Paramotors for Teat Data Ueed

\begin{tabular}{c|c|c|c|c}
\hline \hline Test series & $\begin{array}{c}\text { Bent } \\
\text { points } \\
(1)\end{array}$ & $\begin{array}{c}f_{1}^{\prime}, \text { in pounds } \\
\text { per square inch } \\
(3)\end{array}$ & $\begin{array}{c}E_{c}, \text { in pounds } \\
\text { per square } \\
\text { inch times } 10^{*} \\
(4)\end{array}$ & $\begin{array}{c}d_{\mathrm{a}} \text {, in } \\
\text { inches } \\
(5)\end{array}$ \\
\hline Walsh-No. 1 & three & $524^{*}$ & $3.299^{*}$ & 0.5 \\
Walsh-No. 2 & three & $538^{*}$ & $4.082^{*}$ & 0.5 \\
Walsh-No. 3 & three & $378^{*}$ & $2.593^{*}$ & 0.5 \\
Walsh-No. 4 & three & $377^{*}$ & $2.715^{*}$ & 0.5 \\
Walsh-No. 5 & three & $686^{*}$ & $4.696^{*}$ & 0.5 \\
Walsh-No. 6 & three & $594^{*}$ & $3.928^{*}$ & 0.5 \\
Mindess & four & $707^{*}$ & 6.260 & 0.375 \\
Huang & three & $410^{*}$ & $3.122^{*}$ & 0.5 \\
Carpinteri & three & $661^{*}$ & $4.173^{*}$ & 0.75 \\
Kaplan-No. 1 & three & $370^{*}$ & 4.190 & 0.75 \\
Kaplan-No. 2 & three & $630^{*}$ & 5.470 & 0.75 \\
Kaplan-No. 3 & four & $370^{*}$ & 4.190 & 0.75 \\
Kaplan-No. 4 & four & $630^{*}$ & 5.470 & 0.75 \\
Shah & three & $378^{*}$ & $3.000^{*}$ & 0.375 \\
Gjørv-No. 1 & three & $482^{*}$ & $3.000^{*}$ & 0.375 \\
Gjgrv-No. 2 & three & $542^{*}$ & $3.180^{*}$ & 0.63 \\
\hline
\end{tabular}

*Asterisk indicates numbers estimated by calculations.

Note: $p s i=6,895 \mathrm{~N} / \mathrm{m}^{2}$, in. $=25.4 \mathrm{~mm}$. 
The more general six-step numerical algorithm described previously was used to analyze the fracture data from the literature $(8,10,11,14$ $17,21,22,25,26)$ concerning three-point and four-point bent specimens (Table 1). All these data were fitted jointly under the condition that $c_{m}$ and $\beta$ have the same value for all the data, while $G_{f}$ may vary from one concrete to another. Table 1 lists all the parameter values needed for the analysis. Table 2 lists the optimum values of fracture energy, $G_{f}$, which yields (in the least-square sense) the optimum fit of the measured maximum loads, based on various choices of parameters $c_{m}$ and $\beta$. The Young's modulus, if not reported by the experimentalist, was estimated as $E=$ $57,000 \sqrt{f_{c}^{\prime}}$ in which $f_{c}^{\prime}$ and $E$ are in pounds per square inch. Only bent specimens were analyzed since, for them, very accurate expressions for the energy release rate are known (Eqs. 5-6). Note also that Eq. 5 is more accurate than that used by Walsh (26). Huang and Carpinteri also reported a second series of tests which was not considered because of an inexplicably large scatter. For some of the test data, $P_{\max }$ was not reported directly, but it could be calculated from the reported nominal stress at failure.

An idea of how closely the theory can describe the maximum load data can be obtained from Figs. 7-8, in which the calculated value, $P_{t}$, of maximum load $P_{\max }$ is plotted versus the measured value $P_{m}$. The values are normalized with regard to the failure loads, $P_{0}$, predicted by the engineering bending theory based on the ligament cross section. For the three-point bent specimen (Fig. 2), $P_{0}=2\left(b d^{2} / L\right) f_{t}^{\prime} / 3$, and for the fourpoint bent specimen $P_{0}=f_{i}^{\prime} b d^{2} / L$.

If the theory were perfect, the plots in Figs. 7-8 would be straight lines of slope 1 passing through the origin. Thus, deviations from the straight line represent errors, and linear statistical regression analysis

\begin{tabular}{|c|c|c|c|c|c|c|}
\hline \multirow[b]{2}{*}{$\begin{array}{c}\text { Test series } \\
\text { (1) }\end{array}$} & \multirow{2}{*}{$\begin{array}{c}\text { Equation } 7 \\
\beta=0.72 \\
c_{m}=1.85 \\
\text { (2) }\end{array}$} & \multicolumn{5}{|c|}{ Equation 8} \\
\hline & & $\begin{array}{c}\beta=0.458 \\
c_{m}=1 \\
(3)\end{array}$ & $\begin{array}{c}\beta=0.665 \\
c_{m}=3 \\
(4)\end{array}$ & $\begin{array}{c}\beta=0.780 \\
c_{m}=6 \\
(5)\end{array}$ & $\begin{array}{c}\beta=0.845 \\
c_{m}=10 \\
(6)\end{array}$ & $\begin{array}{c}\beta=0.911 \\
c_{m}=20 \\
(7)\end{array}$ \\
\hline Walsh-No. 1 & 0.456 & 0.245 & 0.378 & 0.565 & 0.806 & 1.409 \\
\hline Walsh-No. 2 & 0.375 & 0.199 & 0.311 & 0.467 & 0.666 & 1.166 \\
\hline Walsh-No. 3 & 0.290 & 0.156 & 0.240 & 0.358 & 0.511 & 0.893 \\
\hline Walsh-No. 4 & 0.190 & 0.101 & 0.158 & 0.237 & 0.339 & 0.593 \\
\hline Walsh-No. 5 & 0.396 & 0.210 & 0.328 & 0.493 & 0.705 & 1.234 \\
\hline Walsh-No. 6 & 0.449 & 0.240 & 0.372 & 0.557 & 0.794 & 1.389 \\
\hline Mindess & 0.348 & 0.174 & 0.292 & 0.455 & 0.657 & 1.161 \\
\hline Huang & 0.649 & 0.355 & 0.532 & 0.797 & 1.145 & 2.018 \\
\hline Carpinteri & 0.390 & 0.198 & 0.327 & 0.505 & 0.728 & 1.287 \\
\hline Kaplan-No. 1 & 0.362 & 0.184 & 0.303 & 0.465 & 0.668 & 1.178 \\
\hline Kaplan-No. 2 & 0.591 & 0.301 & 0.494 & 0.759 & 1.090 & 1.921 \\
\hline Kaplan-No. 3 & 0.397 & 0.202 & 0.332 & 0.510 & 0.733 & 1.293 \\
\hline Kaplan-No. 4 & 0.536 & 0.273 & 0.448 & 0.689 & 0.989 & 1.743 \\
\hline Shah & 0.165 & 0.083 & 0.138 & 0.212 & 0.303 & 0.533 \\
\hline Gjørv-No. 1 & 0.192 & 0.098 & 0.160 & 0.246 & 0.351 & 0.616 \\
\hline Gjørv-No. 2 & 0.262 . & 0.135 & 0.219 & 0.334 & 0.476 & 0.835 \\
\hline
\end{tabular}
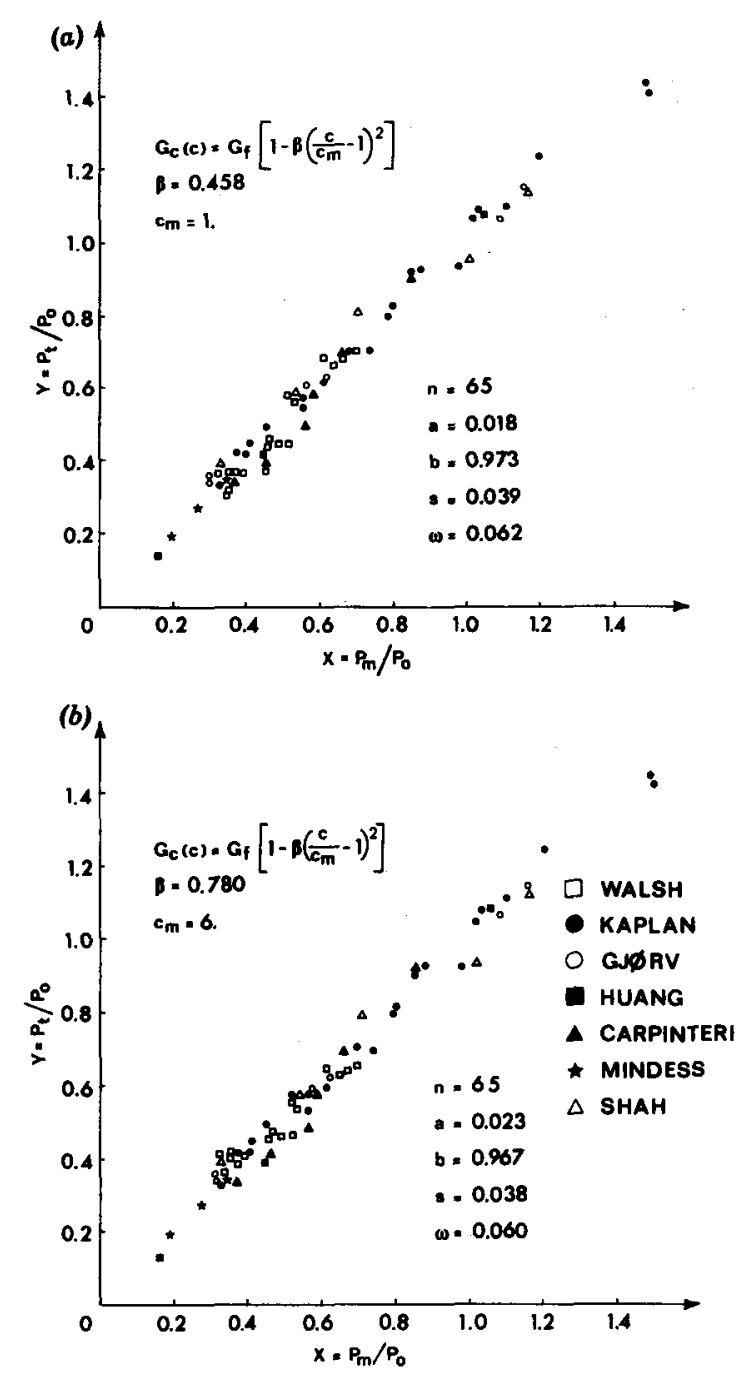

FIG. 7.-Examples of Regressions of Theoretical versus Measured Values of Maximum Loed for Parabolic R-Curve Formula (Eq. 8) and for Varlous Parameter Values

can be applied. The basic statistical parameters are: $s=\left[\Sigma_{i}\left(Y_{i}-Y\right)^{2} /(n\right.$ $-2)]^{1 / 2}=$ standard deviation of the deviations $Y_{i}-Y$ from the regression line; $n=$ number of all data points; $\omega=s / \bar{Y}=$ coefficient of variation; in which $\bar{Y}=\Sigma_{i} Y_{i} / n=$ ordinate of the centroid of all data points. These statistical parameters, along with optimum slope $b$ and $Y$-intercept $a$, are listed in Figs. 7-8.

From extensive statistical computer calculations and data plotting it appears that the presently available fracture data for the maximum load can be roughly equally well approximated by both the exponential and parabolic formulas (Eqs. 7-8), and that a relatively wide range of pa- 


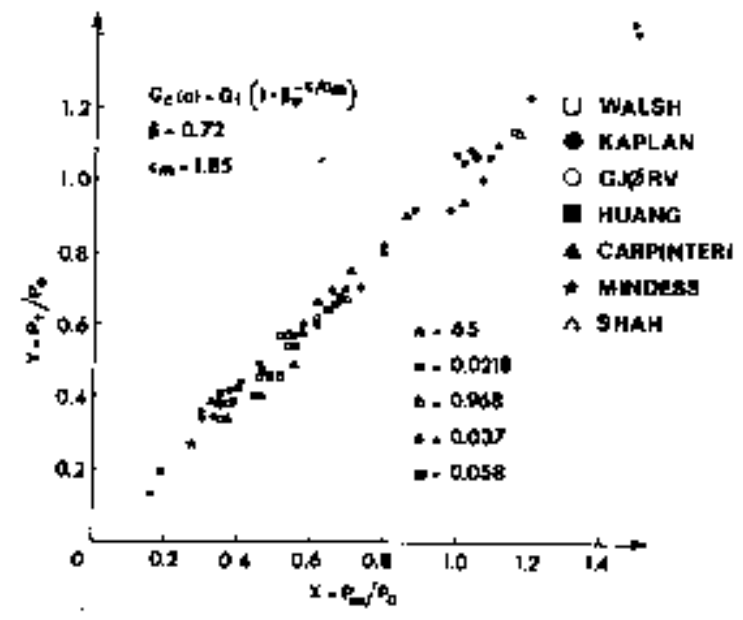

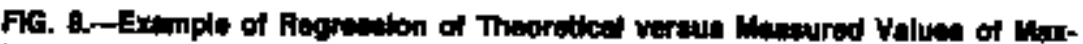

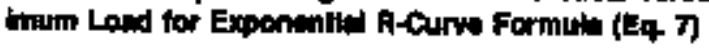

rameter $c_{m}$ yields nearly equally good results [Fig. $7(a-b)$ ]. This finding is the same as that from the aforementioned analysis of the expetimenta R-curves. The value of $c_{m}$ previously determined from the experimental R-curve (Eq. 12) appears to be near optimum for the maximum load data also. Due to the broad range of possible $c_{w}$ values, there is considerable uncertainty in the value of $G_{f}$, since different values of $c_{m}$ yield rather different values of $G_{1}$. These values of course correspond to different crack extensions. To determine $G_{f}$ with more certainty, one would need test data for really large specimens, reaching into much larger rack extensions, $a-a_{0}$, and also, if possibte, direct measurements of crack length $a$ at fallure. The difficulty of the latter is notorious, and the definition of what constitutes the crack length is frought with ambiguity in deciding the crack opening value that delineates a macroscopic crack from ricrocracking.

Despite the uncretainty in determining $c_{\mathrm{m}}$, the present analydis actieves a substantial improvement in the capabilities to fit the existing fracture test data. Using the concept of equivalent or "effective" crack length slone, i.e., without the R-curve, the existing test data cannot be fitted eatisfactorily, as demonstrated in Appendix I.

\section{Comangrow:}

1. Approximate linear elastic fracture analysis allows achieving satisfactory fits of existing fracture data for concrete.

2. Two essential features are needed: (a) The analysis must use an equivalent crack kength instead of the actual notch or crack length as observed; and (b) the fracture energy must be considered as a function of the crack extension (R-curve).

3. The existing test data can be described equally weil with the use of different formulas for the R-curve and different parameter values in the same formula. The fracture energy values depend strongiy on the type of formula used for data evaluztion. This does not seem to be a problem, however, if the same formula is used for both data evaluation and structural anaiysis.

4. The precise shape of the R-curve is not important from the practical viewpoint, however, what are important are the overall slope, the iritia] value, and the final value.

5. Consequenty, sophisticated analyses of the precise shape of R-curves by differential or integral equations make practically no serse for concrete and cannot be verified by existing experimental techniques.

6. A parabola is a convenient expression for the R-curve because it allows solving the failure load from a quadratic equation, if the energy release rate is corsidered to vary linearly with the crack length.

7. For an R-curve of any shape, a simple compitter algonithun to determine the failure load is presented.

8. The length parameter of the R-curve is approximately related to the maximum aggregate size.

\section{ACxnomimesuent}

Partial finarcial support under U.S. Air Force Office of Scientific Research Grant No. 83-0009 to Northwestem University is gratefully acknowledged. The work was done partly during L. Cedolin's Visiting Scholar appointment at Northwestern University, and partly during Z. P. Bažant's Vigiting Professor appointment at Politecnico di Milano, both organized under a cooperative research agreement as part of the U.S.ltaly cooperative science program. Thanks are due to Graduate Research Assistant J. K. Kim for his help in fitting the R-curves, and to Mary Hill for her perfect secretarial services.

\section{Amenox l-Can the R-Curve aE Dispeseod Wmr?}

An inquisitive reader might ask whether the available test data could not be represented equally well by some still simpler theory. The present theory is characterized by two features: (1) An equivalent rather than actual crack length; and (2) the R-curve. Let us now examine two possible formulations in which the second feature, i.e., the concept of the R-curve, is deleted.

Use of Local Sire Parameter.-.-The length of the equivalent crack to be used in approximate linear analysis may be expected to be between $a$ and $\left(a+d_{f}\right)$ in which $a=$ the length of the complete crack; and $a_{f}=$ the length of the fracture process zone ahead of the crack. Therefore, fracture propagation may depend not only on the energy release nate, $W^{\prime}$, for crack length $a$, but also on its increment over length $d_{f}, \Delta W^{\prime}=$ $\left(\partial W^{\prime} / \mathrm{da}\right) d_{f}[\mathrm{Fig} .9(a)]$. By arguments similar to those used by lrwin (13) to estimate the size of the yielding zone in metal fracture, it can be shown that $d_{f}$ mutst equal $c_{1}\left(K_{\alpha} / f\right)^{2}$ in which $K_{\sigma}=$ the criticat value of Mode I stress intensity factor, $K_{1} ; f_{i}^{r}=$ the direct tensile strength of concrete; and $c_{1}=a$ nondimensional constant. Recalling that $K_{*}^{2}=E G_{f}(19)$, we can see that $\Delta W^{\prime} / G_{f}=c_{1} S$ in which we introduce

$S=\frac{E}{f t^{2}} \frac{\partial W^{\prime}}{\partial a}$ 


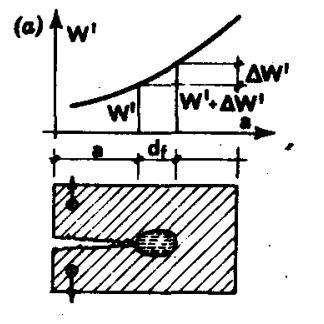

(b)
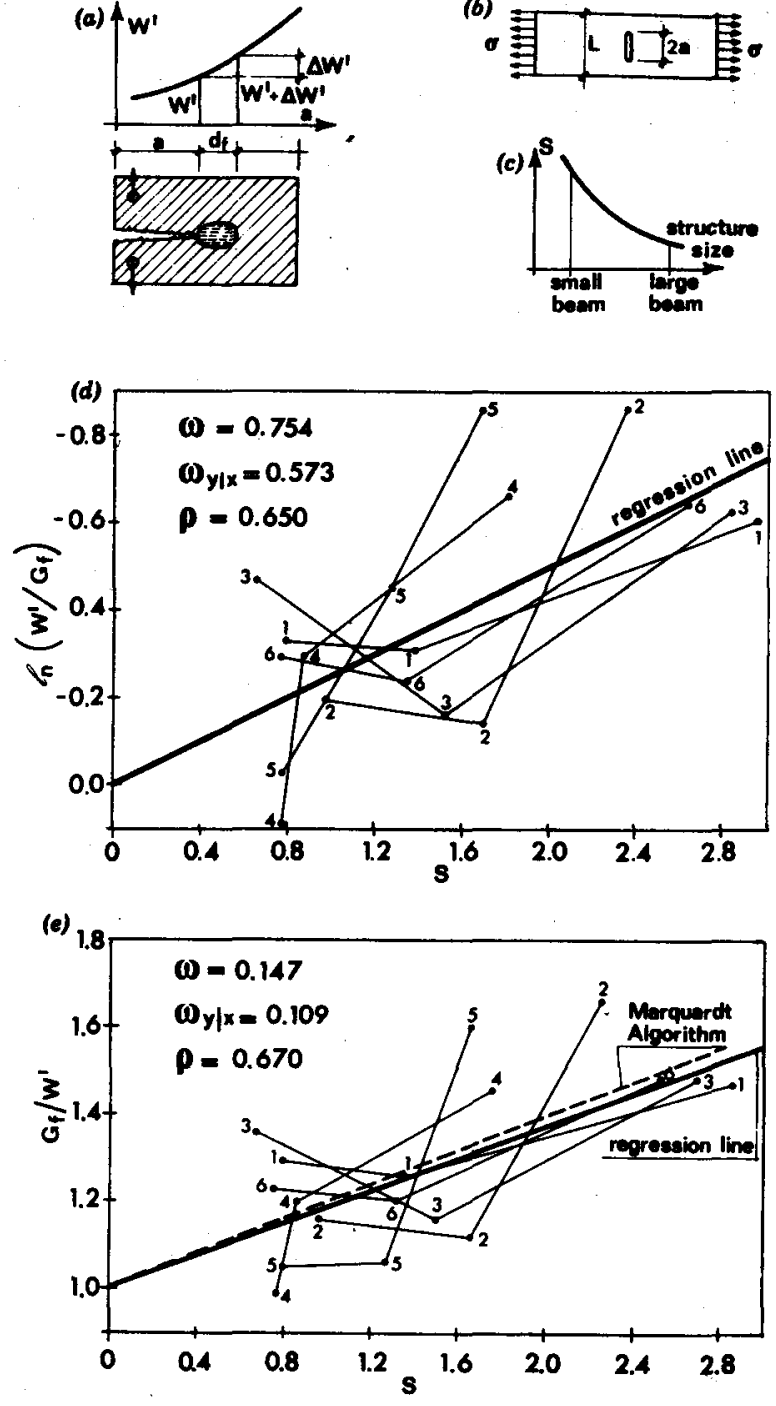

FG. 9.-Local Size Parameter (Eqs. 17, 18) and Beat Data Fits Attalnable without R-Curves

as a nondimensional local size parameter characterizing the change of the energy release rate of the structure over the length of the fracture process zone. Thus, since fracture growth should depend on both $W^{\prime}$ (at length $a$ ) and $W^{\prime}+\Delta W^{\prime}$ (at length $a+d_{f}$ ), we may assume the fracture criterion as

$W^{\prime}=G_{f} F(S)$

instead of the form $W^{\prime}=G_{f}$ used in the classical linear fracture me- chanics (19). $F(\$)$ is an empirical function, to be determined by fitting test data.

Note that through $S$, the criterion in Eq. 18 involves $f^{\prime}$ in addition to $G_{f}$. Also note that parameter $S$ is equivalent to similar parameters involving $\partial W ! / \partial a$ which were recently introduced by Paris and Hutchinson $(12,18)$ and others to approximately characterize the effect of largescale yielding in ductile fracture of metals.

For an illustration of parameter $S$, we may consider an infinite centercracked strip subjected to uniaxial tensile stress $\sigma$ at infinity [Fig. $9(b)$ ]. According to Eq. 4 and the relation $W^{\prime}=K_{I}^{2} / E$, we get from Eq. $17 \mathrm{~S}$ $=\pi P^{2} E^{2}\left[L \cos (\pi a / L) f_{t}^{\prime}\right]^{-2}$. We see that, for similar specimens, $S \simeq 1$ / $L$ and that $S \rightarrow \infty$ for vanishing ligament length, i.e., for $a \rightarrow L / 2$. Accordingly, $F(S)$ should tend to an asymptote as $S \rightarrow \infty$. For small $S$ (large structures) [Fig. $9(c)$ ], $F(S)$ should approach 1.0 since Eq. 18 must reduce to the linear fracture mechanics criterion $W^{\prime}=G_{f}$. The foregoing properties are exhibited, e.g., by the following simple functions

$G=G_{f} \exp \left[-\left(c_{f} S\right)^{p}\right]$

$G=G_{f}\left[1+\left(c_{f} S\right)^{p}\right]^{-r}$

in which $c, p, r=$ empirical constants.

To check the applicability of Eqs. 18-20, the data by Walsh involving three-point bent specimens and six different concrete mixes, were used first. In fitting the data, different values of $G_{f}$ were allowed for each concrete mix, while the values of the parameters $c_{f}, p, r$ in Eqs. 19-20 were considered the same for all concretes. Optimum fits [Figs. $9(d-e)$ ] were obtained by computer minimization of a sum of squared deviations from data, using a library subroutine for Marquardt-Levenberg algorithm.

For Eq. 19 the deviations were determined in the plot of $\ln \left(W^{\prime} / G_{c}\right)$ versus $S$ as shown in Fig. $9(d)$ for the six test series. The coefficient of variation for all data points, $\omega$, and for the deviations of all data points from the regression line, $\omega_{y \mid x}$, and the correlation coefficient $\rho$ are also listed in Fig. $9(d) ; \omega=\left[\Sigma_{i}\left(Y_{i}-\bar{Y}\right)^{2} /(n-1)\right]^{1 / 2}, \omega_{y \mid x}=\left[\Sigma_{i}\left(Y_{i}-Y\right)^{2} /(n-\right.$ 2) $]^{1 / 2} / \bar{Y}, \rho=\left[\Sigma_{i}\left(Y_{i}-\bar{Y}\right)^{2} / \Sigma_{i}\left(Y-Y^{2}\right]^{1 / 2}\right.$, in which $Y_{i}=$ ordinates of data points; $Y=$ ordinates of regression line (at same $S$ ); $\bar{Y}=$ mean of $Y_{i}$; and $n=$ number of all points.

For Eq. 20, the deviations were determined in the plot of $\left(G_{f} / W^{\prime}\right)^{1 / r}$ versus $S$, as shown in Fig. 8(e). The regression line (solid line) slightly differs from the optimum fit line (dashed line) obtained by MarquardtLevenberg algorithm.

If classical linear fracture mechanics were used, then the fits in Figs. $9(d-e)$ would have to be made by horizontal lines. So, the improvement of the fit due to the slope of the line, as indicated by the decrease in $\omega_{y x}$ compared to $\omega$, indicates the improvement attained by virtue of $\mathrm{Eq}$. 18. We see that the improvement is not insignificant. However, the resulting fits are distinctly inferior to those achieved with the R-curve. Note also that the deviations from the optimum fit lines in Figs. $9(d-e)$ reveal a certain systematic trend; see the bend on each of the lines connecting the three points for the same test series. Therefore, we will now examine another possible formulation.

Equivalent Crack Length Based on Aggregate Size.-If the compli- 
cated stress distribution on the crack line is replaced by an elastic distribution, the effect should be insignificant at distances from the crack tip which exceed the size of the fracture process zone, provided the resultants of the distributions are the same. This follows from Saint-Venant's principle. The same location of the resultants can be achieved by replacing the actual crack length $a_{0}$ with a certain equivalent crack length $a>a_{0}$. In the Dugdale-Barenblatt model of crack tip yielding (19) the equivalent crack length can be calculated, but for concrete we can hardly do that because the stress-strain law for the fracture process zone is not known well and also the stress distribution is highly random. Therefore, it seems appropriate to consider $a-a_{0}$ to be an empirical function of the fracture process zone size, $d_{f}$. For that, we could use again the estimate $d_{f} \simeq c_{1}\left(K_{\mathrm{cr}} / f_{t}^{\prime}\right)^{2}$; however, to try another approach, we will exploit the fact that a fully developed fracture process zone has normally the size of several times the maximum aggregate size, $d_{a}$. The use of $d_{a}$ is convenient since, in contrast to $K_{\mathrm{cr}}$ and $f_{t}^{\prime}$, no experiments need be made to determine it.

Thus, we assume that $a=a_{0}+f d_{a}$, in which $f=$ empirical parameter to be determined by fitting test data, and $a_{0}=$ actual crack length, interpreted as the notch length in our subsequent fitting of test data. Since the stress distribution along the fracture process zone should depend also on the change of $W^{\prime}$, we may assume $f$ to depend on $S$, and so we set

$a=a_{0}+f(S) d$

and use, instead of Eq. 18, the failure criterion $W^{\prime}(a)=G_{f}$, in which $G_{f}$ $=$ evaluated at length $a$, rather than $a_{0}$. For the definition of $S(\mathrm{Eq} .17)$ we now evaluate $\partial W^{\prime} / \partial a$ at $a_{0}$ rather than at $a$, since otherwise Eq. 21 would become an implicit equation in $a$. For function $f(S)$, one may simply choose

$$
f(S)=c_{1}+c_{2} \exp \left(-c_{3} S\right)
$$

The values of $G_{f}$ obtained by fitting the data of Walsh's six concretes are plotted in Fig. 10(a) against the $W^{\prime}$-values calculated from measured failure loads. (Note that the $G_{f}$-values are also affected by optimization, because they depend on $a$.) A perfect fit would, in this plot, produce a straight line of slope 1 passing through the origin. The regression line is plotted in Fig. 10(a) as the solid line, and the $95 \%$ confidence limits are plotted as the dashed lines. As is seen, the scatter is small. Thus, the hypothesis in Eqs. 21-22 works well for Walsh's data, much better than the previous hypothesis (Eqs. 17-20).

Subsequently, other data available in the literature were fitted separately, giving a higher scatter than Walsh's data but still acceptable. However, the values of $c_{1}, c_{2}, c_{3}$ obtained by optimizations made individually for each data set differ greatly from each other. Moreover, for the combined optimization of all data, the results of which are shown in Fig. 10(b), the exponential decay of the optimized function $f(S)=c_{1}$ $+c_{2} \exp \left(-c_{3} S\right)$ comes out to be so slow (small $c_{3}$ ) that $f(S)$ is almost a straight line. Therefore, the combined optimization of all data sets has also been tried using a simpler linear expression $f(S)=c_{1}+c_{2} S$, and the regression analysis yielded about the same standard error. It has also
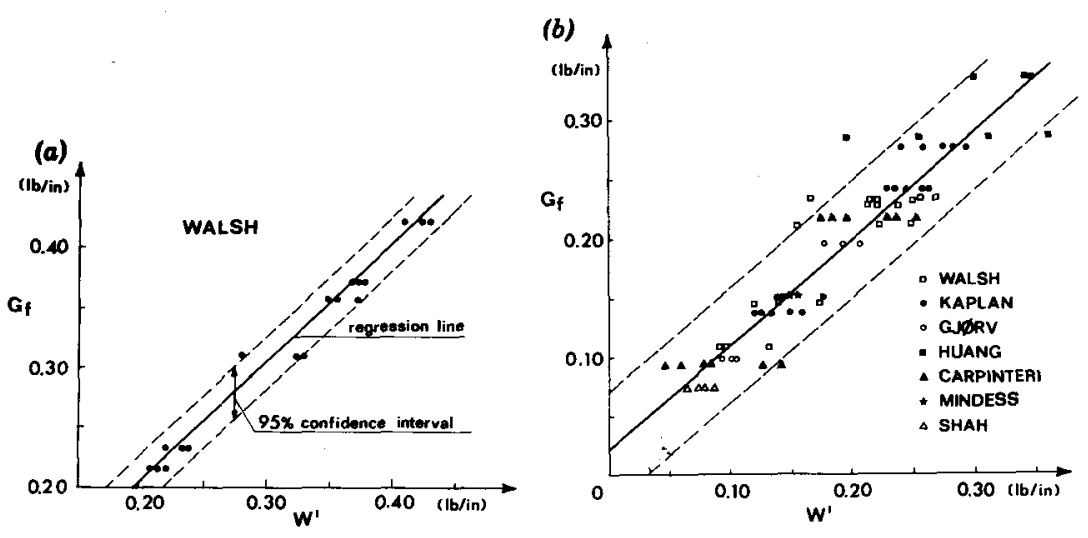

FIG. 10.-Equivalent Crack Length after Eq. 21 and Data Fits Attainable without R-Curves

been tried whether $\mathcal{c}_{1}, c_{2}, c_{3}$ are perhaps some simple functions of concrete properties, rather than constants. In particular, analyses were made with the function $f(S)=c_{1} x+c_{2} y+\left(c_{3} x+c_{4} y\right) S$ and several other more complicated functions, in which $x=1-f_{t}^{\prime} /(1,500$ psi) and $y=1-E /$ $\left(2 \times 10^{7} \mathrm{psi}\right)$. The rationale behind assuming these functions was the fact that, for very high $f_{t}^{\prime}$ or very high $E$, the fracture process zone becomes smaller since the stiffness of the matrix approaches that of the aggregate. However, no improvement in the combined regression of all data could have been achieved in this manner.

We must, therefore, conclude that, without the R-curve concept, the representation of test results attainable with a linear elastic analysis is much worse, although still better than that attainable when the actual crack length is considered.

\section{Appendix II.-References}

1. Bažant, Z P "Crack Band Model for Fracture of Geomaterials," Proceedings, 4th International Conference on Numerical Methods in Geomechanics, Edmonton, Alberta, Canada, Vol. 3, Z. Eisenstein, ed., June, 1982, pp. 11371152.

2. Bažant, Z. P., "Mechanics of Fracture and Progressive Cracking in Concrete Structures," Report 83-2/428m, Center for Concrete and Geomaterials, Northwestern University, Evanston, Ill, Feb. 1983; to appear as Chapter 1 in Fracture Mechanics Applied to Concrete Structures, G. C. Sih, ed., Martinus Nijhoff Publ., The Hague.

3. Bažant, Z. P., and Oh, B. H., "Crack Band Theory for Fracture of Concrete," Materials and Structures (RILEM, Paris), Vol. 16, 1983, pp. 155-177.

4. Bažant, Z. P., and Cedolin, L., "Blunt Crack Band Propagation in Finite Element Analysis," Journal of the Engineering Mechanics Division, ASCE, Vol. 105 No. EM2, Apr., 1979, pp. 297-313.

5. Bant Z P and Cedolin "Fracture Mechanics of Reinforced Concrete," Joumal of the Engineering Mechanics Division, ASCE, Vol. 106, No. EM6, Dec., 1980 (discussion and closure Vol. 108, pp. 464-471).

6. Broek, D., Elementary Engineering Fracture Mechanics, Noordhoff International Publishing, Leyden, Netherlands, 1974. 
7. Brown, J. H., "Measuring the Fracture Toughness of Cement Paste and Mortar," Magazine of Concrete Research, Vol. 24, No. 81, Dec., 1972.

8. Carpinteri, A., "Experimental Determination of Fracture Toughness Parameters $K_{I C}$ and $J_{I C}$ for Aggregative Materials," presented at the Mar. 23-Apr. 3, 1981, 5th International Conference on Fracture, Cannes, France, "Advances in Fracture Research," D. François, ed., Vol. 4, pp. 1491-1498.

9. Entov, V. M., and Yagust, V. I., "Experimental Investigation of Laws Governing Quasi-Static Development of Macrocracks in Concrete," Mechanics of Solids (translation from Russian), Vol. 10, No. 4, 1975, pp. 87-95.

10. Gjørv, O. E., Sorenson, S. I., and Arnesen, A., "Notch Sensitivity and Fracture Toughness of Concrete," Cement and Concrete Research, Vol. 7, 1977, pp. 333-344.

11. Huang, C. M. J., "Finite Element and Experimental Studies of Stress Intensity Factors for Concrete Beams," thesis presented to the Kansas State University, at Kansas, in 1981, in partial fulfillment of the requirements for the degree of Doctor of Philosophy.

12. Hutchinson, J. W., and Paris, P. C., "Stability Analysis of J-Controlled Crack Growth; Elastic-Plastic Fracture," ASTM-STP668, American Society for Testing and Materials, 1979, pp. 37-64.

13. Irwin, G. R., Applied Mathematics Research, Vol. 3, No. 65, 1964.

14. Kaplan, M. F., "Crack Propagation and the Fracture of Concrete," American Concrete Institute Journal, Vol. 58, No. 11, Nov., 1961.

15. Knott, J. F., "Fundamentals of Fracture Mechanics," Butterworth; London, England, 1973.

16. Krafft, J. M., Sullivan, A. M., Boyle, R. W., "Effect of Dimensions on Fast Fracture Instability of Notched Sheets," Cranfield Symposium, 1961, Vol. 1, pp. 8-28.

17. Mindess, S., Lawrence, F. V., and Kesler, C. E., "The J-Integral as a Fracture Criterion for Fiber Reinforced Concrete," Cement and Concrete Research, Vol. 7, 1977, pp. 731-742.

18. Paris, P. C., et al., 'The Theory of Tearing Instability of the Tearing Mode of Elastic-Plastic Crack Growth," ASTM Special Technical Publication, No. 668 and 677,1979 , pp. 5-36.

19. Parker, A. P., "The Mechanics of Fracture and Fatigue," E. \& F.N. Spon, Ltd., London, 1981.

20. Petersson, P. E., "Fracture Energy of Concrete: Method of Determination," Cement and Concrete Research, Vol. 10, 1980, pp. 78-89.

21. Petersson, P. E., "Fracture Energy of Concrete: Practical Performance and Experimental Results," Cement and Concrete Research, Vol. 10, 1980, pp. 91101.

22. Shah, S. P., and McGarry, F. J., "Griffith Fracture Criterion and Concrete," Journal of the Engineering Mechanics Division, ASCE, Vol. 97, No. EM6, Proc. Paper 8597, Dec., 1971, pp. 1663-1676.

23. Sok, C., and Baron, J., "Mécanique de la Rupture Appliquée au Béton Hydraulique," Cement and Concrete Research, Vol. 9, 1979, pp. 641-648.

24. Tada, H., Paris, P. C., and Irwin, G. R., The Stress Analysis of Cracks Handbook, Del Research Corp., Hellertown, Pa., 1973.

25. Visalvanich, K., and Naaman, A. E., "Fracture Model for Fiber Reinforced Concrete," Journal of American Concrete Institute, Vol. 80, Mar.-Apr., 1983, pp. 128-138.

26. Walsh, P. F., "Fracture of Plain Concrete," The Indian Concrete Journal, Vol. 46 , No. 11, Nov., 1979, pp. 469, 470, and 476.

27. Wecharatana, M., and Shah, S. P., "Slow Crack Growth in Cement Composites," Journal of Structural Engineering Division, ASCE, Vol. 108, No. ST6, June, 1982, pp. 1400-1413.

28. Wnuk, M. P., Bażant, Z. P., and Law, E., "Stable Growth of Fracture in Brittle Aggregate Materials," Report, Center for Concrete and Geomaterials, Northwestern University, Evanston, Ill., Oct., 1983; also to appear in Theoretical and Applied Fracture Mechanics, G. Sih, ed., Elsevier-North Holland. 